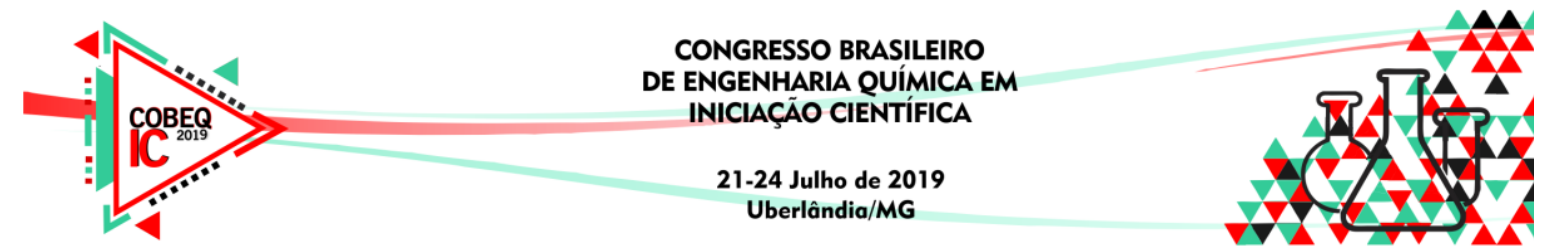

\title{
BIOSORPTION OF DYES IN A SYNTHETIC EFFLUENT BY UNMODIFIED AND MODIFIED Fucus vesiculosus
}

\author{
Y. A. R. LEBRON ${ }^{1}$, V. R. MOREIRA ${ }^{1}$, L. V. S. SANTOS ${ }^{1,2}$ \\ ${ }^{1}$ Pontifical Catholic University of Minas Gerais, Department of Chemical Engineering \\ ${ }^{2}$ Federal University of Minas Gerais, Sanitary and Environmental Engineering Department \\ Contact e-mail: yuri.lebron@ outlook.com
}

\begin{abstract}
Textile industries consume large amounts of water, chemicals and dyes. Therefore, a significant wastewater amount containing these compounds is generated. In this study, the treatment of a synthetic textile wastewater by a species of brown macro algae (Fucus vesiculosus), in addition to the modification process effect on the removal efficiency was carried out. Infrared spectra demonstrated several functional groups on the biosorbent surface linked to the presence of lipids and proteins. The energy dispersive $\mathrm{x}$-ray spectra confirmed the surface modification by sodium hydroxide. Among the dyes present in the wastewater, Rhodamine B was the one with the highest removal efficiency. The modification step was considered advantageous, since the $\mathrm{NaOH}$-modified Fucus vesiculosus showed a 14\% increase in Rhodamine B removal efficiency.
\end{abstract}

\section{INTRODUCTION}

Dyes and pigments are used in several industrial segments, with an estimated global production of $7 \times 10^{5}$ tones (Gürse et al., 2016). Therefore, a significant wastewater amount containing these compounds is generated, which justifies the investigation of economically viable forms of treatment. Among the techniques available are the biological and advanced oxidation processes, which have as disadvantages the possibility of a more toxic byproducts generation and low efficiency due to the recalcitrant nature that dyes present (Yagub et al., 2014). Thus, the adsorption process implying biological materials, defined as biosorption, appears as an alternative to the conventional methods. Among the biosorbents available and of proven efficiency are the algae. They have high biosorption capacity, being easily cultivated in both fresh and salt water, and possibility of storage without losing their properties as biosorbent (Lebron et al., 2018). These advantages could be complemented by modifications in their surface aiming at a greater functional groups and, therefore, effective binding sites availability on their surface.

For this reason, the present work investigates a synthetic textile wastewater treatment by a specie of brown macro algae (Fucus vesiculosus), in addition to the modification process effect on dyes removal efficiency. 


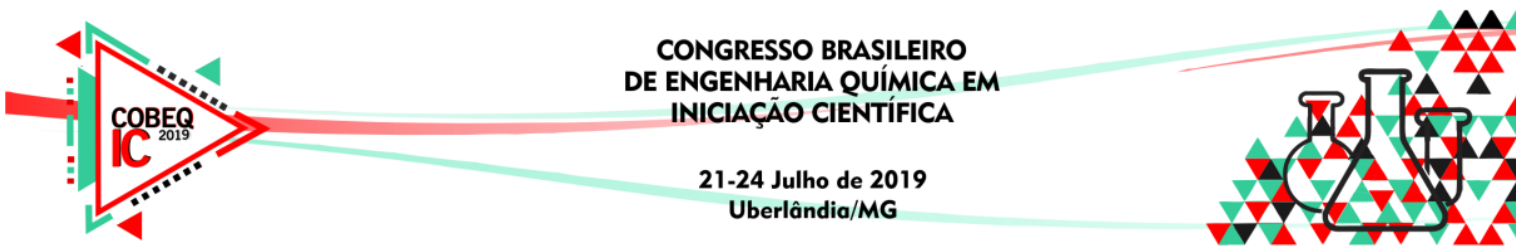

\section{MATERIALS AND METHODS}

\subsection{Biomass activation and characterization}

Part of the algae sample was chemically modified in $50 \mathrm{~mL}$ solution at a 1:2 mass ratio of biomass to sodium hydroxide $(\mathrm{NaOH})$. The system was kept in a shaker (Marconi MA420) under constant agitation $(250 \mathrm{rpm})$ and temperature $\left(28^{\circ} \mathrm{C}\right)$ for $24 \mathrm{~h}$. After that, the sample was filtered and washed with distilled water until a neutral $\mathrm{pH}$. The remaining water was removed in a drying oven at $105^{\circ} \mathrm{C}$ for $2 \mathrm{~h}$, followed by a grinding step in a Wiley mill (Tecnal, TE-680) until it reached a particle size smaller than $250 \mu \mathrm{m}$. The unmodified and modified biosorbent was characterized in terms of its composition and morphology with the aid of the technics ATRFTIR (Shimadzu IRAffinity-1), scanning electron microscopy (SEM), and energy dispersive Xray spectroscopy (EDS), (JEOL JSM IT300).

\subsection{Biosorption experiments}

A synthetic effluent was prepared based on physicochemical parameters reported in the literature (Aouni et al., 2012; Fersi \& Dhahbi, 2008). In general, effluents from the textile segment present high alkalinity $(\mathrm{pH} 10-12.5)$ and an intense color. Moreover, the dying and printing processes commonly adopt the use of $\mathrm{NaCl}$ and $\mathrm{Na}_{2} \mathrm{CO}_{3}$ in order to favor the dyes integration into the fibers (Aouni et al., 2012). The textile wastewater was prepared from standard solutions and the $\mathrm{pH}$ adjusted with a $\mathrm{NaOH}$ solution $0.1 \mathrm{~mol} / \mathrm{L}$. The parameters $\mathrm{pH}$ (APHA 4500), conductivity (APHA 2510) and turbidity (APHA 2130) were determined according to the Standard Methods for the Examination of Water and Wastewater recommendations. Color (HACH, DR 3900) and TDS (Hanna, HI2030) were determined using an internal calibration curve. Dyes concentrations were quantified in terms of absorbance at their respective wavelengths. Sodium, potassium, calcium and manganese concentrations were determined using an atomic absorption spectrophotometer (Shimadzu, AA-7000) and an external calibration curve $\left(R^{2}>0.99\right)$. All measurements were performed in triplicate and the mean value for each parameter is presented in Table 1.

Table 1 - Synthetic textile wastewater characteristics. ${ }^{a}$ Absorbance value at: Methylene blue $=$ $665 \mathrm{~nm}$; Eriochrome black T $=525 \mathrm{~nm}$; and Rhodamine B $=554 \mathrm{~nm}$

\begin{tabular}{|c|c|}
\hline Parameter & Value \\
\hline \hline $\mathrm{pH}$ & $7.22 \pm 0.03$ \\
\hline Conductivity $(\mu \mathrm{S} / \mathrm{cm})$ & $310 \pm 1$ \\
\hline Turbidity $(\mathrm{NTU})$ & $26.80 \pm 0.61$ \\
\hline $\mathrm{TDS}(\mathrm{mg} / \mathrm{L})$ & $114 \pm 2$ \\
\hline Color $^{(m g ~ P t-C o / L)}$ & $11850 \pm 354$ \\
\hline Methylene Blue $^{\mathrm{a}}$ & $0.789 \pm 0.197$ \\
\hline Eriochrome Black T $^{\mathrm{a}}$ & $17.311 \pm 0.452$ \\
\hline Rhodamine B $^{\mathrm{a}}$ & $36.132 \pm 0.773$ \\
\hline Sodium $(\mathrm{mg} / \mathrm{L})$ & $457.35 \pm 2.75$ \\
\hline
\end{tabular}




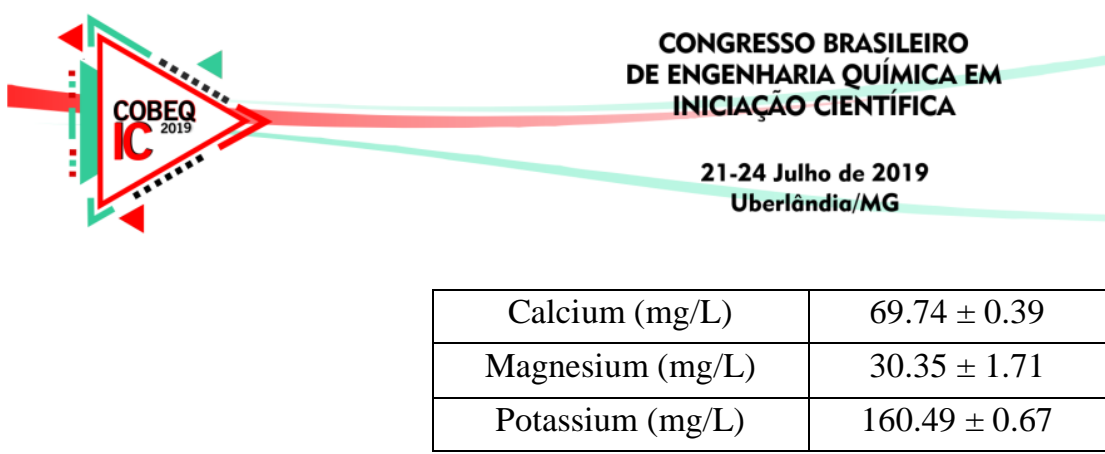

The wastewater remediation process was conducted in a $50 \mathrm{~mL}$ amber glass test tubes containing $10 \mathrm{~mL}$ medium and a biosorbent concentration of $2 \mathrm{~g} / \mathrm{L}$. The system was kept under constant agitation $(250 \mathrm{rpm})$ and temperature $\left(30{ }^{\circ} \mathrm{C}\right)$ for $4 \mathrm{~h}$. At the end, the samples were filtered with a $0.45 \mu \mathrm{m}$ PVDF syringe filter to determine the physicochemical parameters reduction. The removal efficiency (\%Removal) was determined by Equation 1 , where $C_{0}$ $(\mathrm{mg} / \mathrm{L})$ and $C_{e}(\mathrm{mg} / \mathrm{L})$ corresponds to the initial and equilibrium concentration, respectively.

$$
\% \text { Removal }=100\left(C_{0}-C_{e}\right) / C_{0}
$$

\section{RESULTS AND DISCUSSION}

\subsection{Fucus vesiculosus activation and characterization}

Infrared spectra (Figure 1) demonstrated several functional groups on the biosorbent surface. Among them are the stretches in the region of 3257 (-OH stretching), 1747 ( $\mathrm{C}=\mathrm{O}$ stretching) and $1595(\mathrm{C}=\mathrm{O}$ stretching stretching $) \mathrm{cm}^{-1}$, corresponding to functional groups that comprise carbohydrates, lipids and proteins. New functional groups were also observed after the activation process, detected between the regions of 1700 and $1350 \mathrm{~cm}^{-1}$. The characterization was complemented by the SEM images (Figure $2(a, b)$ ), which presented a non-homogeneous biosorbent surface. Apparently, no visible surface modification was observed, however the EDS spectra confirmed the alteration as the compositions varied (Figure 2 (c, d)). Among the elements present, carbon and oxygen are the major components.

Figure 1 - ATR-FTIR spectra before and after the modification process.

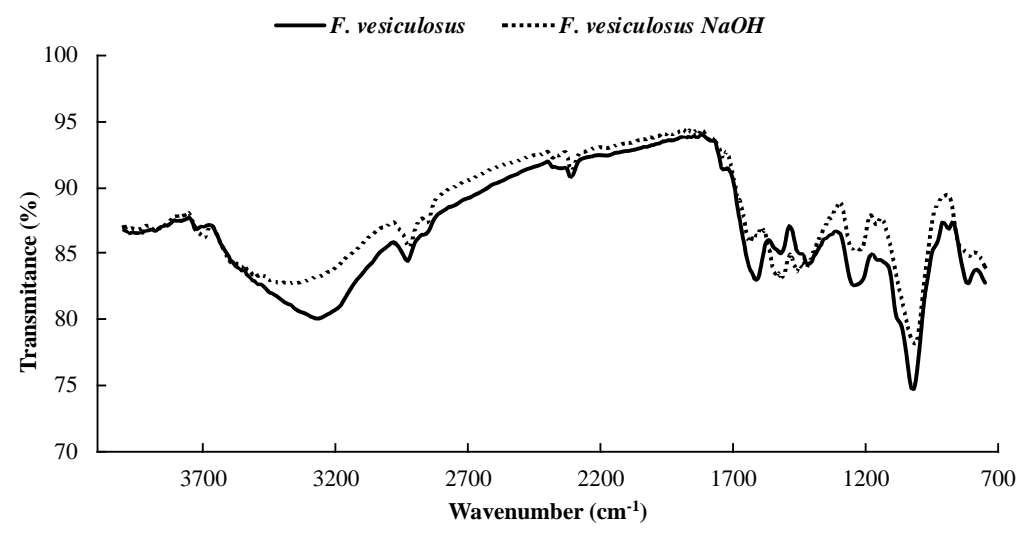




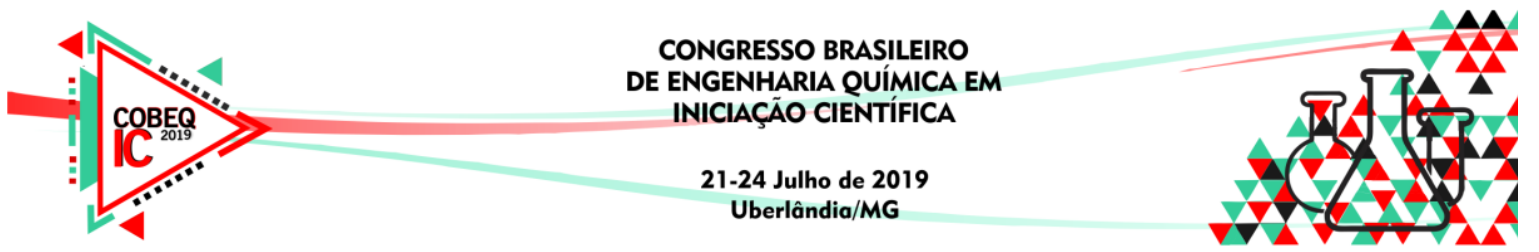

Figure 2 - SEM-EDS images at magnification $100 \mathrm{x}$ and $20.0 \mathrm{kV}$ for the $(\mathrm{a}, \mathrm{c})$ unmodified and $(\mathrm{b}, \mathrm{d})$ modified $F$. vesiculosus samples.

(a)

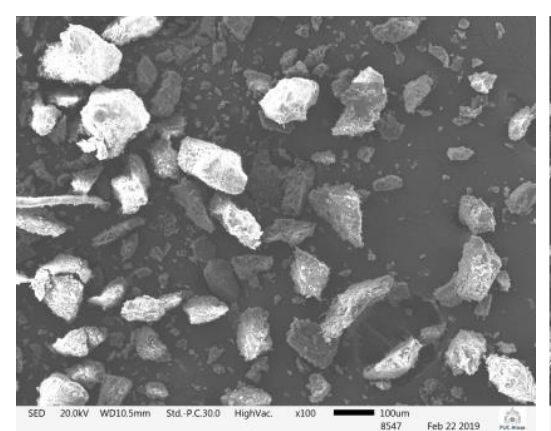

(c)

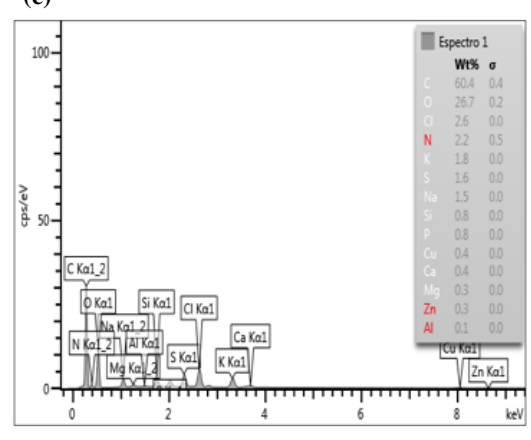

(b)

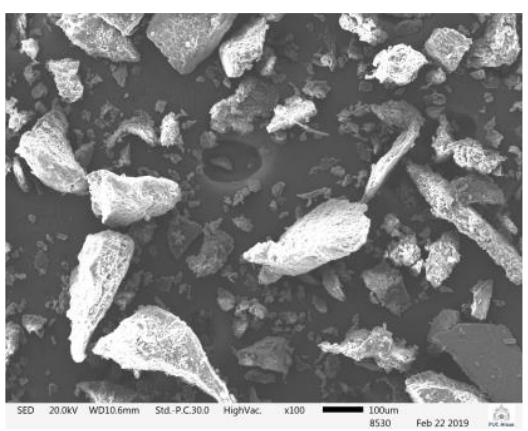

(d)

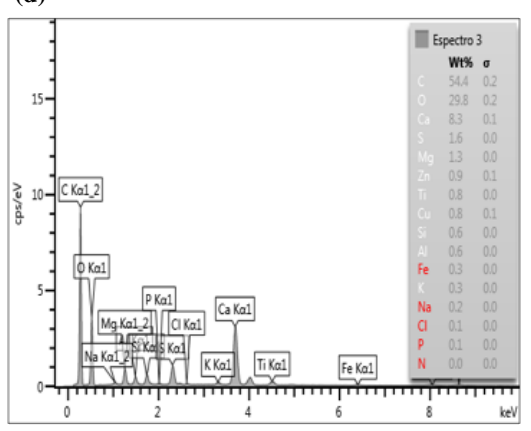

\subsection{Textile wastewater treatment}

Among the dyes present in the wastewater, Rhodamine B was the one with the highest removal efficiency, followed by ET and MB (Table 2). They present in their molecular structure different functional groups that favor their interaction with the active sites present on the biosorbent surface. As part of the ion exchange mechanism involved in the biosorption process, it is expected a replacement of the ions that constitute the algae sample to the cationic and anionic dyes species, therefore, contributing to their removal.

Table 2 - Contaminants removal from textile wastewater by biosorption onto unmodified and modified Fucus vesiculosus

\begin{tabular}{|l|c|c|}
\hline & $\begin{array}{c}\text { \%Removal } \\
\text { unmodified }\end{array}$ & $\begin{array}{c}\text { \%Removal } \\
\text { modified }\end{array}$ \\
\hline \hline Methylene Blue & $28.96 \pm 2.76$ & $22.64 \pm 2.30$ \\
\hline Eriochrome Black T & $46.73 \pm 0.32$ & $47.16 \pm 8.70$ \\
\hline Rhodamine B & $51.11 \pm 2.54$ & $59.52 \pm 2.72$ \\
\hline Sodium & $89.67 \pm 9.09$ & $89.76 \pm 0.15$ \\
\hline Calcium & $71.99 \pm 1.83$ & $45.08 \pm 1.12$ \\
\hline Magnesium & $>99.7 \pm 0.35$ & $>99.7 \pm 0.22$ \\
\hline Potassium & $>99.7 \pm 0.24$ & $>99.7 \pm 0.31$ \\
\hline
\end{tabular}

Furthermore, NaOH-modified Fucus vesiculosus showed an increase in the removal efficiency of Rhodamine B, Eriochrome black T and sodium. Being the maximum increase of 


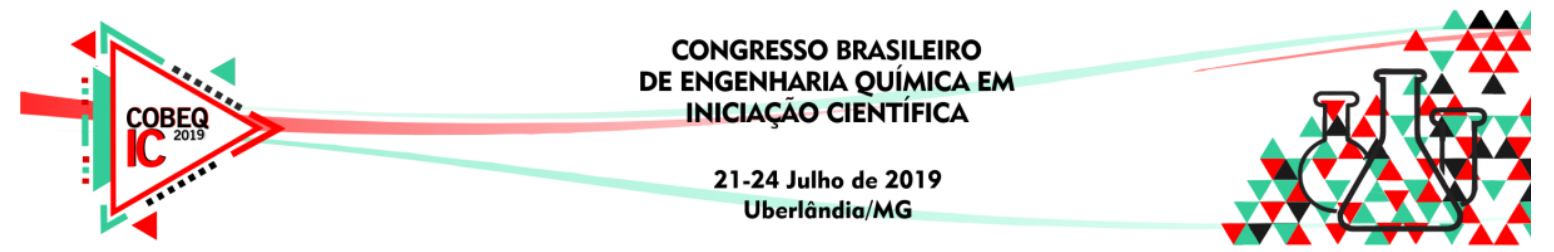

$14 \%$ (Rhodamine B), showing that the algae modification step is advantageous for increasing its efficiency.

\section{CONCLUSIONS}

For many years, the color removal has been set as an objective of several studies, which was hampered due to the complex composition and recalcitrant behavior that textile wastewater presents. The presence of salts in these effluents is mainly due to the dyeing and finishing steps and, once associated with caustic conditions that these effluents present, can directly affect the aquatic environment. For these reasons, the use of $F$. vesiculosus biomass for textile wastewater treatment process was considered promising, proven by the high removal capacity of salts, in addition to dyes, present in aqueous solutions. Furthermore, the algae modification step was considered advantageous since it increases its efficiency.

\section{REFERENCES}

AOUNI, A. et al. Reactive dyes rejection and textile effluent treatment study using ultrafiltration and nanofiltration processes. Desalination, v. 297, p. 87-96, 2012.

FERSI, Cheïma; DHAHBI, Mahmoud. Treatment of textile plant effluent by ultrafiltration and/or nanofiltration for water reuse. Desalination, v. 222, n. 1-3, p. 263-271, 2008.

LEBRON, Y. A. R. et al. Remediation of methylene blue from aqueous solution by Chlorella pyrenoidosa and Spirulina maxima biosorption: Equilibrium, kinetics, thermodynamics and optimization studies. Journal of Environmental Chemical Engineering, v. 6, p. 6680-6690, 2018.

GÜRSES, A. et al. Dyes and pigments: their structure and properties. Dyes and Pigments. Springer, Cham, p.13-29, 2016.

YAGUB, M.T. et al. Dye and its removal from aqueous solution by adsorption: A review. Advances in Colloid and Interface Science, v. 4, n. 2, p. 154-162, 2014. 